\title{
RESIGNIFICANDO LA PATERNIDAD, CRIANZA Y MASCULINIDAD EN PADRES POST DIVORCIO
}

\author{
REVALUING PATERNITY, BREEDING AND MASCULINITY IN PARENTS POST \\ DIVORCE
}

\author{
Nelson Zicavo M. ${ }^{1}$ - Angelo Fuentealba V. \\ Universidad del Bio-Bio, Chillán, Chile. \\ (RECIBIDO 5/11/2012 - ACEPTADO 15/12/2012)
}

\begin{abstract}
RESUMEN
Artículo que aborda los principales hallazgos investigativos derivados del estudio de las visiones significativas de los hombres acerca del ejercicio de su paternidad post divorcio, desde sus propias construcciones identitarias de masculinidad. El cuidado de los hijos/as, es el resultado de asignaciones socioculturales y relaciones de poder, esto sumado a conflictos conyugales mal manejados (y limitaciones jurídicas), implican para ellos la imposibilidad -impuesta- de participar en la crianza de sus hijos/as. La transgresión al derecho jurídico relacional padre e hijo/a, frecuentemente deriva en reducción del vínculo parental hacia contactos difusos que permiten espacios para manipulaciones; obstrucción y eliminación del rol paterno, negando la necesidad afectiva recíproca y vulnerando el derecho infantil a contar con ambos padres para su crianza armónica.
\end{abstract}

Palabras claves: divorcio, paternidad, crianza, masculinidad.

\begin{abstract}
Article dealing with the main research findings derived from the study of significant visions of men about the practice of their paternity after divorce, from their own identity constructions of masculinity.

The children's care is the result of sociocultural assignations and power relations in addition to conjugal conflicts conducted wrongly (and legal limitations); this implies for them the impossibility -imposed- to participate in the breeding of their children.

The transgression to law regulations related to father and children frequently results in the reduction of the parental link towards diffuse contacts that permit opportunities for manipulations; obstruction and elimination of the father's role, denying the mutual affective necessity and damaging the children's right to rely on both parents for their harmonious breeding.
\end{abstract}

Keywords: divorce, paternity, breeding, masculinity.

1 Psicólogo, investigador y docente de Psicología Universidad del Bío-Bío, Chillán, Chile. Mail: nzicavo@ubiobio.com 


\section{INTRODUCCIÓN}

El problema de investigación se construye desde las condiciones que imposibilitan al padre la crianza de sus hijos/as y permiten entonces la extirpación de sus funciones parentales, la obstrucción del vínculo, la aislación impuesta y la vulneración del derecho jurídico. Estos fenómenos se reproducen socioculturalmente a través de asignados que empíricamente comprenden acciones legales, sociales y psicológicas que al impedir u obstruir el contacto relacional paternal, resultan ser dañinas para la crianza y desarrollo socio afectivo del niño/a.

El ejercicio parentofilial y las subjetividades de paternidad se desarrollan en un contexto histórico-espacial de transición demográfica caracterizado por profundas trasnformaciones socioculturales, nuevas configuraciones familiares y parentalidades emergentes que presionan los sistemas de género, las estructuras patriarcales y normas tradicionales del modelo hegemónico. La "familia tradicional" y su dinámica es influida por nuevos referentes culturales globalizados, que actúan como fuerzas transformadoras del orden social en sus variadas dimensiones humanas, entre paradigmas de producción y satisfacción de necesidades “...la vida en un solo mundo" Giddens (2006). La modernidad se manifiesta en la estructura social y particularmente al interior de la familia tradicional, en la diversificación en su estructura ${ }^{1}$ y las nuevas formas de relacionarse ${ }^{2}$, ambas condicionadas por la creciente independencia económica de la mujer y la participación de varones tanto en la crianza de sus hijos/as como en labores domésticas. En ese sentido, los procesos de individuación restan importancia a los vínculos de origen y matrimonio, haciendo permeable el modelo de familia nuclear como organización universal, por lo que "los diferentes modos de vida que asume la familia les sigue una mudanza de creencias” Jiménez (2005).

Existe consenso entre los investigadores respecto de la importancia de la familia como núcleo de reproducción, subsistema de integración social, espacio de convivencia afectiva, cuidado, protección y formación socializadora para los niños/ as. No obstante, la práctica jurídica indica que frente al divorcio o separación vincular, generalmente la mujer se hace cargo (por imposición o elección) de la crianza y educación de los hijos/as, situación que se radicaliza cuando se proyecta el conflicto relacional de pareja a la díada parental, desencadenando desigualdad de derechos y disociación vincular del niño/a hacia su padre, producto de la obstrucción ejercida por la madre, quién paralelamente se verá limitada en su incorporación a la vida productiva.

En definitiva, nuestro objetivo fue comprender las representaciones significativas del rol parentofilial, elaboradas por padres no custodios post separación/divorcio o desvinculación de su relación de pareja, particularmente aquellos que sufren o han sufrido obstrucción de vínculo y eventualmente desparentalización en la 8va. Región del Bío-Bío, Chile, desde la construcción de sus propias masculinidades.

1 En la 8va región (Chile) hay 503.018 hogares monoparentales de los cuales 150.890 tienen jefatura femenina INE.

2 Por cada 10 matrimonios se registraron 7,5 divorcios en la 8va región (Chile): Servicio Registro Civil 2012. 


\section{MÉTODO}

El estudio se basa en el paradigma cualitativo, cuyo diseño metodológico es flexible, de carácter no experimental y de corte transeccional e inductivo. Es exploratorio, dado que se pretende conseguir un acercamiento entre las teorías adscritas y la realidad objeto de estudio, todo lo cual se ilustra en las siguientes posturas metodológicas que conforman su sentido y procedimiento:

Paradigma cualitativo: "Comprende la conducta humana desde el propio marco de referencia de quien actúa, asume una realidad dinámica...” Barrantes, (2000).

Epistemológicamente fenomenológico: “....apuesta por una fenomenología de la familia que entiende la realidad a través de la subjetividad de los actores sociales, como una actividad reflexiva e interactiva y donde el análisis del discurso y las narrativas sea el protagonista...”. Jiménez (2005).

Método estudio de caso: “...su mayor fortaleza radica en que a través del mismo, se mide y registra la conducta de las personas involucradas en el fenómeno estudiado", Yinn(1993).

Técnica entrevista en profundidad: "constructo comunicativo, en donde los discursos constituyen un marco social de la situación de la entrevista. De esta manera, se podrían analizar e interpretar los aspectos significativos diferenciales de las representaciones de los sujetos investigados”. Alonso 1994 en Valles (2000).

Unidad de Análisis: La unidad de análisis se constituyó voluntariamente por cinco varones entre 28 y 50 años de edad, que construyeron sus representaciones e imaginarios de paternidad en el contexto espacial de la 8va. región del Bío-Bío, Chile, durante los años 2010 - 2011 y que presentaron las siguientes características intencionadas: han convivido con sus hijos/as; vivencian un proceso post divorcio o separación de la díada parental en un escenario de tuición monoparental a favor de la madre; que presentaran firme intención de ejercer una paternidad responsable expresada en la voluntad de participación activa en las funciones parentales con sus hijos/as; que no sufrieran alguna discapacidad que les impidiera expresarse por medio del habla o la escritura.

Análisis de datos: El procesamiento de la información se orientó a convertir los fenómenos simbólicos -registrados tanto en discursos como en prácticas- en datos contenidos en un cuerpo de conocimiento científico, "disminuir la cantidad de información recogida y la elaboración de un mapa conceptual. El sentido del análisis de datos en la investigación cualitativa consiste en reducir, clarificar, sintetizar y comparar la información con el fin de obtener una visión lo más completa posible de la realidad objeto de estudio" Tesh, en Pérez (1994). 
Estructura de análisis según Tesh

\begin{tabular}{|c|c|}
\hline $1^{\text {a }}$ Fase & Desarrollo de categorías desde los datos: análisis exploratorio \\
\hline $2^{a}$ Fase & $\begin{array}{l}\text { Partición del texto en segmentos aplicando las categorías desde los datos: análisis } \\
\text { confirmatorio }\end{array}$ \\
\hline $3^{a}$ Fase & $\begin{array}{l}\text { a) Examen de todos los segmentos en cada categoría a fin de establecer patrones } \\
\text { en cada dato: descripción/interpretación } \\
\text { b) Establecer conexiones entre categorías de datos: sugerir o considerar } \\
\text { posibilidades de relaciones. }\end{array}$ \\
\hline
\end{tabular}

En síntesis, el análisis se inicia con una aproximación teórica al problema y contexto, desde donde se desprenden los objetivos y preguntas de estudio. Posteriormente, se procesó la información recogida en los discursos de los entrevistados, organizándola en temas, subtemas y dimensiones operacionales contenidas en una malla temática, que orientó el análisis de datos y la interpretación desde un nivel conceptual más profundo, haciendo de la reflexión una verdadera integración de saberes entre lo empírico y teórico.

Para sustentar la validez y confiabilidad del estudio se utilizó la triangulación, que según Cohen y Manion 1989 en Ruiz (2004) “...busca la combinación de metodologías en el análisis de los datos para el establecimiento de conclusiones". Por último, se identificaron algunos criterios éticos rectores del estudio en un documento que fue firmado por los entrevistados, donde manifestaron su consentimiento informado a participar en esta investigación.

\section{RESULTADOS}

\section{Asignados socioculturales y Construcción de identidades masculinas frente al ejercicio del rol paterno filial.}

La construcción identitaria masculina influenciada por visiones hegemónicas tradicionales (dada por la vinculación patriarcal, hombre proveedor, exitoso públicamente y distante emocionalmente), es superada por transformaciones que se desprenden de cambios en las condiciones de reproducción material de la vida. Los entrevistados presentan significaciones positivas con relación a la participación como padre en la crianza de los hijos/as, equidad de género y apertura emocional. Ellos conciben como imprescindible su figura paterna en la construcción de sus propios referentes identificatorios, más allá de alguna ausencia de expresiones afectivas (gestuales) de sus progenitores. La identidad del varón es condicionada por el acceso de la mujer al trabajo y los procesos de autonomía femenina, que repercuten en la exclusividad del asignado cultural de desarrollo laboral, el cual es representado como una oportunidad de crecimiento personal y bienestar familiar que demanda mayor complementariedad doméstica, ejercicio compartido de roles parentales, crianza compartida y redistribución de sus tiempos. Perspectiva que se opone al asignado cultural de obligada distancia paternal, asociación lineal al poder 
y proveeduría del padre frente al término conyugal. Por lo tanto, se reafirma la parentalidad como proceso en construcción y cambio constante, cuya práctica es afectada por las condiciones de contexto que influyen en la forma de vinculación parental y en las representaciones emergentes de "subjetividad social" que superan lo atribuido como natural, deconstruyendo los roles de género, para luego volver a construirlos desde la equidad, el bien común, el interés superior del niño/a y los derechos fundamentales. Implica ir en contra del sentido de propiedad de los hijos/ as, con cierta exclusividad de crianza materna y asimetrías parentales; elementos internalizados culturalmente mediante la socialización femenina en perjuicio de la figura paterna.

El modelo dominante de masculinidad con sus imaginarios estereotipados en lo simbólico es cuestionado, supone alejarse de su raigambre mitológica de instinto materno, cuyo asignado cultural impone una pauta excluyente de masculinidad que considera al varón incapaz para cuidar al niño/a y una feminidad que atribuye a la mujer competencias idóneas y naturalizadas, lo cual incentiva la práctica machista de desapego y contribuye a la obstaculización paterno-filial. Esta situación se radicaliza en la separación de la díada parental que es condicionada por normas legales estructurantes, propias de la tradición cultural que regula el tipo de custodia y vínculo parental permitido e impuesto en Chile, la cual lleva a la desvalorización del rol de padre, al distanciamiento obligado y la desparentalización involuntaria de la figura masculina; violentando de esta manera la necesidad afectiva del niño/a y el derecho jurídico al vínculo con ambos padres.

La paternidad ha sido representada como una experiencia significativa, construida en el vínculo con sus hijos/as, en la trascendencia de su rol, en el compromiso afectivo, en el involucramiento activo en funciones parentales y acompañamiento en los procesos de desarrollo psicológico y emocional del niño/a, desde un sentido de responsabilidad moral. Las representaciones subjetivas de responsabilidad parental grafican y confirman que durante la relación de pareja al padre se le exige y valida en la complementariedad de roles y en la cercanía emocional de vínculo con sus hijos/as. Demanda social que una vez terminada la relación de pareja, en un escenario de disputas por conflictos mal manejados es extinguida por una de las partes que la excluye cuando debiera garantizarla, legitimando la tuición monoparental, reproduciendo el alejamiento del padre, la sobreexplotación del rol materno e imágenes carenciadas de figura paterna en los niños/as. Por lo tanto, el término de la relación de pareja es sentido como un acontecimiento que les arrebató la cotidianidad con sus hijos/as y por tanto, se torna extremadamente difícil de llevar a cabo el concepto de parentalidad competente de Arés 2004 en Ramírez, (2011).

En consecuencia, más allá de la concepción social que entiende al padre como prescindible y secundario en la crianza (con el riesgo de producir padres ausentes y desentendidos de su función), se evidencia en los discursos, imaginarios sociales de alta valoración y trascendencia respecto de su vinculación afectiva con sus hijos/ as, en un contexto que combina lo jurídico y lo prescrito socialmente. 


\section{Sistema de tuición imperante, sus manifestaciones en la crianza activa y su validez como garante de la relación paterno-filial}

El estudio grafica que las representaciones sobre el ejercicio de la paternidad post separación de pareja, son condicionadas por el marco jurídico imperante, que impulsa como regla básica los cuidados personales y/o tuición monoparental a favor de la madre. Dicha legislación es percibida como carente de fondo argumental objetivo, que opera bajo un tipo de prejuicio que limita la participación activa del varón en la crianza de sus hijos/as y vulnera el derecho al vínculo emocional entre ambos. Por lo tanto, la norma jurídica se hace parte de las condiciones que reproduce desigualdades de género frente al ejercicio parental y no resulta un aporte positivo al desarrollo de una sociedad basada en los derechos humanos. Empíricamente, se materializa una excesiva burocracia en los procedimientos jurídicos e inoperancia de mecanismos que cautelen el ejercicio parental del padre, lo que acarrea ausencia paterna impuesta y repercute en daño, inestabilidad y fragilidad en el niño/a involucrado en la dinámica de conflicto.

La discriminación de género al ejercicio activo de la paternidad se grafica en una sanción social y jurídica diferenciada para varones respecto de mujeres, sanción que impide al niño/a mantener vínculo con el otro padre que no posee la custodia, todo lo cual genera en éste tensión, dolor, incertidumbre y sensaciones de injusticia frente a temas paralelos como tuición, fijación de alimentos y distanciamiento geográfico. En este sentido y frente al asignado sociocultural de distancia, se observa en los relatos de los sujetos de estudio su convicción de asumir la responsabilidad en la crianza integral de sus hijos/as, lo que se constituye en fundamento frente a la posibilidad de que la norma legal de tuición monoparental a favor de la madre (a priori), pueda ser reemplazada por un estudio dirigido a evaluar las competencias parentales de ambos padres, antes de dirimir el sistema de crianza a implementar, lo que pudiera asegurar la coparentabilidad de roles, el desarrollo armónico de ambos miembros de la expareja y el desarrollo emocional del niño/a. En esa misma línea, se evidencian representaciones positivas sobre un régimen alternativo de "tuición compartida", el cual emerge de países desarrollados y el que culturalmente pareciera requerir de muchos avances para ser aplicado legalmente a nivel local.

Se evidencian en los relatos una oposición explícita frente a consideraciones que señalan históricamente al hombre como un ser emocionalmente distante de sus hijos/as. De acuerdo a Martínez (1996), estaría operando allí un prejuicio, ya que argumentan que las distintas manifestaciones de paternidad responden a diferentes valoraciones que cada cultura considera como necesario e importante desarrollar en un momento histórico, conforme a las determinantes que imponen las relaciones de producción de la vida material.

El contexto de distanciamiento obligado de sus hijos/as provoca en los varones impotencia, pena y sensación de pérdida. Estos varones enarbolan la relación mutua de necesidades afectivas con sus hijos/as, las cuales representan para ellos un aspecto central en sus historias de vida. El vínculo construido desde el apego emocional y el compromiso afectivo (cariños, besos, palabras, abrazos, juegos, 
gestos, ocupación doméstica cotidiana, etc.) se distancia de prescripciones hegemónicas, como el distanciamiento obligado y la obstrucción de vínculo, que resultan ser experiencias muy dolorosas que desean revertir mediante una relación de persona a persona con sus niños/as, tal como señala Ferrari (1999) “...pero ahora lo único que mantendrá la relación entre padre e hijo será la comunicación (persona a persona)".

En consecuencia, existe preocupación en los entrevistados por la lógica práctica del sistema, que fomenta la construcción de imágenes carenciadas de referente paterno y posibilita mecanismos que presionan la subjetividad del niño/a. Se generan incongruencias respecto de la figura de su padre del cual debe alejarse, no importando cuan bien pudiera haber desarrollado su rol y sus funciones parentales de apego, con todo el daño emocional y la vulneración al derecho fundamental de paternar, no favoreciendo la armonía y afecto requerido por los infantes.

En definitiva, las representaciones sociales que construyen los sujetos de estudio superan el divorcio parental impuesto por la perspectiva biologicista que naturaliza la exclusividad materna y el asignado de distancia emocional del padre con sus hijo/as. En materia de cuidados personales no es posible operar con criterios generalizadores, la conveniencia y eficacia de un régimen definido de custodia, debiera estar condicionado por la especificidad y competencia parental de cada familia en particular, no obstante la crianza compartida (Zicavo-Ferrari, 2011) obtiene mayor consenso que la monoparental.

\section{Obstaculizadores de vínculo, desparentalización y el proyecto de paternidad activa en el proceso de crianza de sus hijos/as.}

Las representaciones elaboradas por los sujetos del estudio, respecto a las manifestaciones de obstrucción de vínculo con sus hijos/as se dividieron en aquellas conductas arraigadas en la tradición sociocultural y otras que se vinculan al desacato de imperativos jurídicos por parte de la figura femenina, quien en ocasiones no cumple las disposiciones legales (o agrega obstáculos) impidiendo el contacto entre padres e hijos/as. Estas conductas se traducen en arbitrarios traslados de los niños/as a otras ciudades, los esconden, exponiéndolos a conflictos de lealtades, manipulaciones y denostación del rol del padre en presencia de ellos. En ocasiones, a esto se suma el aprovechamiento y menoscabo económico por parte de quién debería ser su contraparte en la crianza de los hijos/as y lo que es peor -paradójicamente- mientras se obliga al padre a distanciarse del niño/a convirtiendo su figura en prescindible, se da un traspaso de responsabilidades de crianza a personas poco idóneas, generando asimetrías en las figuras parentales. Las relaciones de poder entre los padres empeoran por disputas mal manejadas que sitúan al niño/a en un segundo plano en un afán de ganar-ganar y así concretar la revancha que provoca distanciamiento obligado e impedimentos para ejercer la paternidad. El sistema legal, no en pocas ocasiones se constituye en un marco que impone barreras y posibilita la acción indiscriminada y maliciosa de medidas precautorias de desalojo, prohibición de acercamiento con el resultado de quitar al padre no solo del hogar común sino de la vida de sus hijos/as. El Estado no estaría 
haciendo lo suficiente para garantizar el vínculo del niño/a con ambos padres, tal como lo expresa la Convención de los derechos del niño/a suscrita por Chile. Revertir esta situación ha demandado en los varones entrevistados sufrimiento, devastación, cansancio y un sinnúmero de actividades que implican gran esfuerzo emocional, laboral y económico.

Las representaciones de obstaculización de vínculo en los entrevistados da cuenta de un proceso nocivo y doloroso que les afecta muy profundamente, donde se consigna daño emocional causado a sus hijos/as y la evidencia empírica de "conducta aprendida" originada en su distanciamiento obligado. En ese escenario, las figuras paternas han desarrollado acciones desesperadas para restablecer el vínculo con sus hijos/as, incluso arriesgando el incumplimiento de medidas precautorias, para hacer frente a manipulaciones y compromisos no asumidos por la figura materna, cuestión que se evidencia en expresiones lingüísticas de los hijos/as y en la utilización maliciosa de servicios profesionales a fin de subjetivarlos de acuerdo a su conveniencia.

Los relatos convergen con asignados arraigados culturalmente como el concepto (mito) de instinto materno que naturalizan el vínculo y legitiman socialmente a la figura femenina como referente principal, como la única persona competente para ejercer la crianza de los hijos/as, lo que además otorga sentido de propiedad y extirpa en los niños/as su condición de sujetos de derecho, en contraposición a la legislación vigente y suscrita por Chile. Se reproduce socialmente en discursos posesivos de autoridad femenina, donde el hombre tiende a desaparecer de lo cotidiano por la desvalorización de su rol de padre y la denostación personal; realidad que contrasta significativamente con la construcción integradora y demandante de participación masculina en las funciones parentales que fuera emplazada durante la convivencia conyugal de los padres.

Un condicionante importante de vínculo son las condiciones materiales propias de la globalización que influyen en la relación de distancia entre el ejercicio parental del varón y sus hijos/as, lo que es confirmado por la encuesta sobre participación de los hombres en la crianza de sus hijos/as, Sernam (2010). Esta señala que el $80 \%$ de los encuestados considera que en Chile las condiciones de trabajo dificultan la conciliación entre vida familiar y vida laboral, produciéndose una notable incoherencia entre lo que se espera socialmente del rol de padre y las condiciones que la misma sociedad provee a los varones para ejercer dicha responsabilidad.

En lo que se refiere al proceso de desparentalización desarrollado por Ramírez, (2011), se concluye la existencia de un sistema de conflicto ínter genérico que sigue manteniendo su statu quo, sin modificaciones importantes en las condiciones psicosociales que fundamentan la mutua agresión entre los géneros, donde uno de sus efectos emergentes e invisibles, es la desparentalización intencionada dirigida a extirpar la responsabilidad parental del padre y por consiguiente su práctica cotidiana de crianza. Dicho proceso es reafirmado jurídicamente y legitima un tipo de relación a distancia entre padre e hijos/as, mediante la incorporación de determinadas subjetividades e interpretaciones de paternidad. La base jurídica afianza 
el proceso de desparentalización mediante la premisa de un sistema de tuición determinada que proporciona mucha seguridad a la figura femenina y fomenta relaciones de poder asimétricas, donde las funciones de paternidad se conciben erróneamente solo al interior de la relación de pareja o matrimonio, pasando al olvido -no inocente- una vez terminada la relación conyugal. No obstante, los relatos grafican una crítica emergente hacia un tipo de paternidad desarrollado históricamente por la tradición patriarcal que no aporta al proceso de parentalización, ni tampoco a la redistribución de funciones parentales y equidad de género en la relación dinámica entre lo subjetivo, lo social y lo legal. Se evidencia como expectativa relacional entre padre e hijos/as una visión integradora cuyas representaciones se orientan al concepto de corresponsabilidad, complementariedad de funciones y coparentalidad de roles en el proceso de crianza, más allá de ser simples colaboradores, lo cual supone una firme convicción moral de cuidarlos y aportar en su madurez emocional, ubicando el interés superior del niño/a como eje central.

Por último, las representaciones surgidas en la experiencia de ser padres favorecen un sentido de realización, gozo y satisfacción personal en la construcción identitaria, que a la vez proveen compromiso afectivo y responsabilidad parental como proyecto de vida en un contexto de igualdad de derechos y equidad de géneros.

\section{DISCUSIÓN}

La integración analítica de los diferentes discursos, permite afirmar que la elaboración de significaciones de paternidad y sentido que esta alcanza en la crianza no custodia, es condicionada por procesos de construcción identitario sistemático iniciado mucho antes del nacimiento de los hijos/as, donde los asignados propios de la tradición hegemónica prescriben estereotipos de masculinidad en el imaginario social e individual, que influyen decisivamente en el ejercicio parental, en tanto pauta de reproducción simbólica que contribuye a legitimar la proveeduría y consolidan la distancia de la figura paterna.

Sin embargo, se observa una reorganización de la vida familiar caracterizada por discursos de ruptura con los antiguos patrones relacionales, entre los que emergen nuevas expresiones de lo femenino y lo masculino, con variaciones en los significados de "ser padre" y sus nuevas prácticas. Se presionan las relaciones parentales en el conflicto ínter géneros, ocasionando redistribución de funciones, complementariedad de roles y flexibilización de tiempos dedicados a la crianza de los niños/as, proceso que es exacerbado por un contexto de transformación sociocultural $^{3}$ acelerado por ajustes en las relaciones de producción de la vida material, y específicamente en su eje central "la distribución del trabajo", que hace perder a los varones su calidad de proveedores exclusivos, influyendo en sus identidades, en las relaciones de género, en las concepciones de autoridad y jefatura de hogar.

3 La influencia de la racionalidad neoliberal y su especificidad expansionista constante aplicada a la esfera económica, funciona como fuerza transformadora del orden social en la mayoría de los países a nivel global, en el mundo moderno. 
Por lo tanto, se superan lentamente aquellas representaciones identitarias construidas desde la tradición cultural, permitiendo al varón abrirse a una paternidad activa fundada en lo emocional, dando luces respecto a la lenta retirada de arcaicos mecanismos que actúan como reproductores de asimetrías de géneros, como son la socialización maternal de la mujer y el sentido de propiedad y exclusiva responsabilidad de cuidados de sus hijos/as.

La parentalidad está determinada por factores endógenos y exógenos, premisa que fundamenta cuestionamientos a miradas biologicistas que naturalizan el vínculo con la madre y la preconciben como única fuente de amor incondicional en desmedro de la paternidad, que es entendida como un rol prescindible de carácter periférico "la parentalidad humana es un proceso psicológico complejo, que no se define solo por el hecho biológico de procrear; cuando nace un hijo/a, nace un padre o se repite una ausencia” Arés 2000 en Ramírez, (2011).

En consecuencia, la noción de parentalidad competente como proceso complejo, dinámico y multidimensional debe fortalecerse en situación post divorcio o separación conyugal, y no significar el alejamiento o deterioro de la relación padre e hijos/as, como se desprende de la visión hegemónica que incorpora diversas formas de discriminación en las dinámicas relacionales que atentan contra la equidad de géneros y el respeto a los derechos fundamentales, todas aspiraciones irrenunciables de la humanidad.

La paternidad representa una necesidad de desarrollo afectivo y oportunidad de crecimiento en otras áreas, más allá del rol de proveedor o reproductor. Surge como exigencia social que exhibe contradicciones en dos momentos sustantivos: mientras la relación de pareja existe es deseable, recomendable y se exige al padre públicamente que se involucre en la crianza de sus hijos, mientras que luego del término de la relación de la díada parental se fomenta y se muestra complacencia con que el rol de paternar se transforme en visitas restringidas, proveeduría e indefiniciones respecto de las condiciones en que la sociedad concebirá su figura, ahora distante.

Por último, a nivel jurídico la relación directa y regular no resulta ser suficiente garantía para el desarrollo pleno y armónico del niño/a, ya que en la práctica se constituye en un régimen de visitas, generalmente traducidas en un período de tiempo breve, esporádico y manipulable que no cuenta con medidas concretas que garanticen la igualdad de derechos y oportunidades de vínculo emocional presente y permanente para ambos géneros con sus hijos/as. Se grafica en situaciones de vulneración, barreras al contacto, obstrucción/ruptura de vínculo y desparentalización de la figura paterna que se ven agravadas al ser realizadas por la propia madre. La práctica jurídica con la pensión de alimento y el régimen de visitas estaría reproduciendo el asignado cultural de "hombre proveedor y distante emocionalmente" Zicavo, (2010). 


\section{CONCLUSIONES}

La deconstrucción/construcción de roles de géneros debe ser orientada a terminar con la distancia impuesta a la figura paterna sobre el niño/a y a contrarrestar la dominación naturalizada mediante lo simbólico.

Un progenitor que unilateralmente impide el vínculo entre el niño/a y el otro padre, ejerce abuso y vulnera sus derechos. La distancia impuesta anula su rol e impone el ostracismo a su figura, para luego ser borrada toda imagen paterna en la identidad del niño/a. No hay ningún fundamento que justifique moralmente "olvidarse" del niño/a y erradamente centrarse en el conflicto. Esto es abuso, maltrato infantil.

El eje de la parentalidad debe basarse en la calidad de las relaciones padres-hijos/ as y no en las relaciones de los cónyuges separados.

Las relaciones de producción configuran un conflicto importante entre el tiempo demandado para hacer frente a la competitividad requerida en el imaginario de éxito capitalista y el tiempo necesario para compartir con los hijos/as, con la familia; lo que trae frustración pero también una demanda emergente de redistribución de responsabilidades en materia de crianza.

Resulta imperativo el pleno reconocimiento del hijo/a como sujeto de derecho, "derecho a preservar el vínculo con ambos padres", Declaración de Langedac (1999).

Los padres deben contar con igualdad de status, derechos, responsabilidades y tiempos de convivencia en la crianza de sus hijos/as, garantizando lazos paternofiliales más seguros post separación o divorcio.

La crianza es una oportunidad de desarrollo para ambos padres: para el varón será una oportunidad de desarrollar una paternidad activa y vínculo emocional con sus hijos/as a través de nuevas funciones que superan arcaicos asignados culturales propios del patriarcado y para la mujer el ejercicio equitativo de roles de género y la posibilidad de diversificar su acción cotidiana en busca de una sociedad más justa y sustentadora de los derechos fundamentales de las personas.

Establecer legalmente que frente a una situación de separación de pareja y/o divorcio se realice un estudio de competencias parentales y custodia más adecuado para el niño/a en un análisis particular de cada familia. Significaría eliminar la premisa jurídica y naturalizada de tuición a favor de la madre y disminuir la lucha de poderes ínter géneros impulsada por prejuicios sobre la figura paterna.

Establecer la tuición compartida como una alternativa válida para la crianza de los hijos/as: corresponsabilidad parental, alternancia de convivencia y distribución económica balanceada. Promover la capacitación de funcionarios del sistema judicial en temáticas de familia, pues los conocimientos sobre esta área deben ser actualizados. 
Promover y legitimar la autonomía en los padres para alcanzar acuerdos sobre crianza compartida, en casos de divorcios contenciosos, centrando el asunto en el interés superior del niño/a, con la supervisión de un equipo técnico interdisciplinario debidamente capacitado.

Por ultimo, resulta significativo y trascendente la importancia del vínculo entre padre e hijos/as haciendo de la paternidad un desafío como aspecto central en la construcción de sus historias de vida, en una relación mutua de necesidades y compromiso afectivo construido desde el apego emocional con sus hijos/a. La subjetividad masculina evidencia interés en la corresponsabilidad en la crianza, complementariedad de funciones, coparentalidad responsable y flexibilización de roles domésticos.

\section{REFERENCIAS BIBLIOGRÁFICAS}

Barrantes, R. (2000). Investigación: un camino al conocimiento. Un enfoque cualitativo y cuantitativo. San José Costa Rica. Euned, p72.

Declaración de Langedac, (1999). Conferencia Internacional sobre la Igualdad Parental. Francia.

Ferrari, J. (1999). Ser Padres en el tercer milenio. Mendoza, Canto Rodado, p13-189.

Ferrari, J., Zicavo, N. (2011). Padres Separados, como criar juntos a sus hijos. México, Trillas.

Giddens, A. (2006). Sociología, $5^{\circ}$ edición. Madrid, Alianza, p69.

Jiménez, A. (2005). La familia poliforme una cultura de sentidos: modelos y realidades de la familia actual, $1^{\circ}$ edición, Madrid, Fundamentos, p.16-25.

Martínez, M (1996). Análisis Psicosocial del Prejuicio. Madrid, Síntesis, p15.

Pérez, G. (1994). Investigación Cualitativa: retos e Interrogante. Madrid, La Muralla, V2. p80.

Ramírez, D. (2011). Del proceso de violencia, en la desparentalización a la crianza compartida en equidad. Costa Rica, Univ. Autónoma de Centro América, p14.

Ruiz, G. (2004). Internet y la investigación científica: el uso de los medios y las nuevas tecnologías en la educación, Bogotá, Magisterio.

Valles, M. (2000). Técnicas cualitativas de investigación social, reflexiones metodológicas y práctica profesional. Madrid, Síntesis S. A.

Yin, R. (1993). Applications of Case Study Research, Applied Social Research Methods Series (Vol. 34), Newbury Park, CA, Sage.

Zicavo, N. (2010). Crianza Compartida: síndrome de alienación parental, padrectomía, los derechos de los hijos ante la separación de los padres. México, Trillas. 


\section{REFERENCIAS WEB}

Gobierno de Chile, Sernam, Padres del Bicentenario: Encuesta exploratoria sobre participación de los padres en la crianza de sus hijos e hijas, (2010), Santiago, [en línea] < http://estudios.anda.cl/estudio.aspx?id_estudio $=4424>$ [consulta: 02 Agosto 2011].

Registro civil, < http://www.registrocivil.cl/> [consulta: 09 Mayo 2012]. Instituto Nacional de Estadísticas. Población y Sociedad Aspectos demográficos 2008 [en línea] http://www.ine.cl/canales/chile_estadistico/demografia_y_vitales/demografia/ pdf/poblacion_sociedad_enero09.pdf [consulta: 10 Julio 2011]. 